\title{
Is a Strategy Focused on Super-Utilizers Equal to the Task of Health Care System Transformation? No.
}

\author{
Warren Polk Newton, MD, MPH ${ }^{1,2}$ \\ Ann Lefebvre, MSW, $\mathrm{CPHQ}^{1,2}$ \\ 'Department of Family Medicine, University of North Carolina School of Medicine, Chapel Hill, North Carolina \\ ${ }^{2}$ North Carolina Area Health Education Centers, University of North Carolina, Chapel Hill, North Carolina \\ Ann Fam Med 2015;13:8-9. doi: 10.1370/afm.1747.
}

S uper-utilizers are like a siren song. If we could just heal these people, the reasoning goes, we will save enough money to invest in other important social needs, such as education and housing. For family physicians, the song is particularly seductive. Super-utilizers often combine multiple comorbid conditions with behavioral health challenges and poor living conditions, making them a wonderful fit for broadly trained family physicians who are comfortable working with teams across the continuum of care addressing behavioral and social problems. At last, family physicians become clinical rock stars, practicing heroic medicine like the cardiac surgeons of yesteryear. And it gets better: identifying hotspots can be done with relatively simple data systems, providing a portal for beginning to address the social determinants of disease and social justice.

A nice story-but perhaps too nice. We believe instead that a focus on super-utilizers as a sole strategy for health transformation may in fact distract from the real opportunities of health care reform and possibly harm the evolution of primary care.

A critical first issue is definition: super-utilizer according to whom? It is no accident that insurance companies and their foundations have been major funders of the development of strategies for implementing superutilizer interventions. The story of a patient getting over $150 \mathrm{CT}$ scans in a year sells copy

Conflicts of interest: authors report none.

\section{CORRESPONDING AUTHOR}

Warren Polk Newton, MD, MPH

William B. Aycock Distinguished Professor \& Chair

UNC Department of Family Medicine

CB\#7595 William B. Aycock Building

Chapel Hill, NC 27599-7595

Warren_Newton@med.unc.edu and fits anyone's definition of a super-utilizer. In practice, however, an insurer desiring to tier physicians according to costliness differs from practices responding to complex patients and their needs. The elasticity of the concept-the top $1 \%, 5 \%$, or $10 \%$ of utilization, denominators that vary by 3 orders of magnitude and vastly different protocols for refreshing and reviewing these populations-makes launching a "super-utilizer" intervention relatively easy. But this variation has huge implications for clinical strategy and makes evaluation and sustainability more difficult. Caveat emptor!

Beyond definitions is the question, on which population do we want to focus? An important distinction is between high utilizers and high utilizers we can do something about. Community Care of North Carolina, ${ }^{1,2}$ which has served as a model for Medicaid reform in many states, routinely distinguishes between these 2 populations. A focus on super-utilizers alone misses waste. There are many super-utilizers with conditions that prevent acute intervention, such as cancer patients getting a bone marrow transplant, and many patients who do not reach the threshold to be labelled "superutilizers," but there are still great opportunities for efficiency. Another important distinction is between the "expensive" and the "about to become expensive:" the decision of when we should intervene varies from population to population. For example, in our regional uninsured initiative, ${ }^{3}$ the greatest initial savings have not been from a few individuals with dramatic stories-the proverbial burned-out schizophrenic with a coagulopathy living under a bridgebut rather from those patients receiving a primary care home and from simple case management for patients visiting the Emergency Department.

The focus on utilization alone, both by itself and as a proxy of overall cost, is also problematic, allowing the belief to persist that our health care problems boil down to cost only. This belief allows us to ignore our perva- 
sive problems with quality of care $^{4,5}$ and patient experience. ${ }^{6}$ We must keep the Triple Aim in mind. Moreover, for insurers, foundations, and most importantly the clinically integrated systems that now employ the majority of family physicians, super-utilizer interventions seem a quick fix. Such interventions are attractive because they focus on dramatic cases and are amenable to a targeted, strategic initiative. The Advisory Board and several insurance companies are now promoting "extensivist" programs targeted at super-utilizers. In many settings, this is drawing investment away from the hard work of transforming primary care, by adding yet another layer to the multitude of providers serving a patient in a still fragmented delivery system.

Finally, sustainability of improvement projects is challenging, both programmatically and financially. Let us be humble: it is difficult to sustain outcomes over time. Regression to the mean explains the faltering of many reported successful quality improvement projects. There is an increasingly robust literature on sustainability of improvement programs; for example, for chronic care, sustained and committed leadership, culture change, incentives, staff development and job descriptions, and patient engagement are critical for long-term success. Of course, payment mechanisms for super-utilizer interventions will be critical. What else will be necessary for sustaining success?

So what is the role of super-utilizer interventions in the evolution of primary care? Our advice: don't be seduced by the siren song. The danger is in the distraction from the challenging and unsexy work of evolving the patient-centered medical home and improving the medical neighborhood.,8 The key will be building super-utilizer interventions into office systems that can truly support patient populations with their varying levels of care by using an engaged and appropriately resourced care team. New approaches to advanced access scheduling that can address superutilizer patients (and transitional care), embedded case management, IT systems necessary to drive care management, capacity to intervene outside of the office setting, and community-based infrastructure to coordi- nate efforts with social services are all requirements of adequate office systems. ${ }^{9,10}$ Targeting a population on cost alone will not get us to where we need to go.

To read or post commentaries in response to this article, see it online at http://www.annfammed.org/content/13/1/8.

Key words: health services, utilization; efficiency/organization; family medicine; patient-centered medical home; $\mathrm{PCMH}$; super-utilizer; care coordination; delivery of healthcare; health expenditures; social determinants of health; resource allocation

Submitted September 16, 2014; submitted, revised, November 24, 2014; accepted November 26, 2014.

\section{REFERENCES}

1. Steiner BD, Denham AC, Ashkin E, Newton WP, Wroth T, Dobson LA Jr. Community care of North Carolina: improving care through community health networks. Ann Fam Med. 2008;6(4):361-367.

2. Community Care of North Carolina. http://www.communitycarenc. com. Accessed Sep 12, 2014.

3. Denham AC, Hay SS, Steiner BD, Newton W/P. Academic health centers and community health centers partnering to build a system of care for vulnerable patients: lessons from Carolina Health Net. Acad Med. 2013;88(5):638-643.

4. Institute of Medicine. To Err is Human: Building a Safer Health System. Washington, DC: National Academy Press; 2000.

5. Institute of Medicine and Committee on Quality of Health Care in America. Crossing the Quality Chasm: A New Health System for the 21st Century. Washington, DC: National Academy Press; 2001.

6. Davis K, Stremikis K, Squires D, Schoen C. The Commonwealth Fund. Mirror, mirror, on the wall, 2014 update: how the U.S. health care system compares internationally. http://www.commonwealthfund.org/publications/fund-reports/2014/jun/mirror-mirror. Published Jun 16, 2014.

7. Donahue KE, Newton WP, Lefebvre A, Plescia M. Natural history of practice transformation: development and initial testing of an outcomes-based model. Ann Fam Med. 2013;11(3):212-219.

8. Newton WP, Lefebvre A, Donahue KE, Bacon T, Dobson A. Infrastructure for large-scale quality-improvement projects: early lessons from North Carolina Improving Performance in Practice. J Contin Educ Health Prof. 2010;30(2):106-113.

9. Daaleman TP, Hay S, Prentice A, Gwynne MD. Embedding care management in the medical home: a case study. J Prim Care Community Health. 2014;5(2):97-100.

10. Taylor EF, Machta RM, Meyers DS, Genevro J, Peikes DN. Enhancing the primary care team to provide redesigned care: the roles of practice facilitators and care managers. Ann Fam Med. 2013;11(1):80-83. 